\title{
Processamento mínimo do melão Cantaloupe com uso de doses de cloreto de cálcio e quelato aminocálcico
}

\author{
Francisca Ligia de C Machado'; Ricardo E Alves²; Ebenézer de O Silva² \\ ${ }^{1}$ UFERSA, C. Postal 137, 59625-900 Mossoró-RN; ²Embrapa Agroindústria Tropical, C. Postal 3761, 60020-181 Fortaleza-CE; \\ elesbao@cnpat.embrapa.br
}

\section{RESUMO}

A qualidade de melão Cantaloupe ‘Hy-Mark’ minimamente processado em cubos, tratado com cloreto de cálcio ou quelato aminocálcico e armazenado sob refrigeração foi avaliada. Os frutos foram colhidos em estádio de maturação comercial, caracterizado por camada de abscisão do pedúnculo com até $75 \%$ de desprendimento, teor de sólidos solúveis mínimo de $9.0^{\circ}$ Brix, coloração externa verde-escuro e firmeza da polpa máxima de 18 N, no Agropolo Mossoró-Assu (RN), e transportados para o laboratório da Embrapa Agroindústria Tropical, onde foram selecionados, sanitizados, processados e tratados a $10^{\circ} \mathrm{C}$. Posteriormente os cubos foram imersos em cálcio a $0,5 \%$ e $1,0 \%$, na forma de cloreto de cálcio e cálcio $0,5 \%$ e $1 \%$ na forma de quelato aminocálcico por três minutos, drenados, acondicionados em embalagens PET e armazenados a $5 \pm 1^{\circ} \mathrm{C}$ e $90 \pm 5 \%$ UR por 18 dias. As análises de aparência, coloração, firmeza da polpa, teores de cálcio total e livre, sólidos solúveis totais, acidez total titulável e pH foram realizadas logo após o processamento e em intervalos de três dias até o décimo oitavo dia. A aplicação de cálcio na forma de cloreto de cálcio e quelato aminocálcico reteve a firmeza da polpa e conservou a aparência das amostras por todo o período experimental, destacando-se principalmente a aplicação de 1,0\% de cálcio na forma de cloreto de cálcio que não só resultou em maior retenção da firmeza, como também proporcionou os maiores teores de cálcio total.

Palavras-chave: Cucumis melo, vida útil.

\begin{abstract}
Fresh-cut of Cantaloupe melon using doses of calcium chloride and calcium amino acid chelate

The quality of fresh-cut Cantaloupe 'Hy-Mark' melon treated with calcium chloride or calcium amino acid chelate and stored under refrigeration was studied. Fruits were harvested at commercial maturity, taking into consideration slip stage when only $25 \%$ of the stem remained intact upon removal from the vine, soluble solids no lower than $9.0^{\circ}$ Brix, firmness no higher than $18 \mathrm{~N}$, and dark green color of the rind. Fruits were transported to the postharvest laboratory, where they were sorted, sanitized, processed and treated at $10^{\circ} \mathrm{C}$. Upon processing, samples were immersed in calcium chloride or calcium amino acid chelate solution containing $0,5 \%$ or $1,0 \%$ of calcium, during three minutes, drained, placed in plastic containers, and stored under $5 \pm 1^{\circ} \mathrm{C}$ and $90 \pm 5 \%$ relative humidity conditions. Evaluations of visual appearance, aroma, color, flesh firmness, soluble solids, titratable acidity, $\mathrm{pH}$, and total calcium content of tissue samples were performed soon after processing and every three days up to the eighteenth day of storage. Application of both calcium salts kept samples visual appearance and resulted in remarkable firmness maintenance. Application of $1.0 \%$ calcium, as calcium chloride, resulted in higher firmness values and greater total calcium content.
\end{abstract}

Keywords: Cucumis melo, storage life.

(Recebido para publicação em 8 de novembro de 2006; aceito em 18 de fevereiro de 2008)

$\mathrm{O}$ processamento mínimo tem ganhado destaque no mercado pela conveniência do consumo imediato e por proporcionar um produto com características sensoriais e nutricionais semelhantes ao fruto intacto. No entanto, operações inevitáveis ao preparo, tais como o descasque e a redução do tamanho, resultam em perda de água e aceleração da ação enzimática, principalmente pelo rompimento do sistema de membranas das células adjacentes ao corte. O processamento contribui também para o aumento na taxa respiratória e da produção de etileno (Saltveit, 2000), ao mesmo tempo em que expõe o produto à contaminação pela remoção da epiderme protetora, favorecendo o crescimento de microorganismos pelo fornecimento de substrato alimentício proveniente dos exsudatos celulares na superfície cortada. Assim, o fruto cortado torna-se ainda mais perecível do que o intacto.

A manutenção da firmeza é um dos principais desafios para a comercialização de produtos minimamente processados uma vez que esta expressa as características sensoriais e funcionais do tecido, que podem ser percebidas não só através do tato, mas também da visão (Szczesniak, 2002). É portanto, fator decisivo para o consumidor na aquisição de frutos e vegetais, especialmente os minimamente processados, prontos para o consumo.

A perda de firmeza, juntamente com contaminações microbiológicas, são os principais problemas associados à qualidade do melão minimamente processado, mesmo quando armazenado sob baixas temperaturas (Aguayo et al, 2008). Esta perda de firmeza esta diretamente relacionada ao nível de cálcio no tecido (Conway, 1989) e pode ser reduzida ou retardada através da adição de cálcio graças à estabilização do sistema de membranas e à formação de pectatos de cálcio capazes de conferir rigidez à lamela média e à parede celular (Poovaiah, 1986).

A perda de firmeza em melão Cantaloupe intacto e minimamente processado tem sido controlada através da aplicação de cálcio nas formas de quelato de cálcio (Lester \& Gruzaak, 1999) e cloreto de cálcio (Luna-Guzmán et al., 1999, Saftener et al., 2003). No entanto, o uso destes produtos não é de todo adequado no processamento do fruto, primeiro por ser um metalosato de 
aplicação foliar (Lester \& Gruzaak, 1999) e o segundo por provocar sabor amargo em concentrações iguais ou acima 2,5\% (Luna-Guzmán \& Barrett, 2000). Assim, faz se necessário o estudo de novos produtos à base de cálcio que sejam eficientes na retenção da firmeza e que possam ser aplicados no fruto minimamente processado. Desta forma, outras fontes de cálcio como o suplemento alimentar quelato aminocálcico devem ser testados na adição ao fruto cortado. O quelato aminocálcico, fabricado pelo laboratório Albion, Clearfield, Uta, EUA, está incluído na lista de produtos com formulação GRAS (Generally Recognized As Safe) do departamento de Agricultura dos Estados Unidos da América (USDA), e os componentes da formulação (n.3515, com 18\% de cálcio) são certificados pela Kosher \& Parve (KOF-K Kosher Supervision of Teaneck, NJ (Albion, 1998)). Este estudo objetivou avaliar a influência da aplicação de baixas doses de cálcio (0,5 e 1,0\%) na forma de cloreto de cálcio e quelato aminocálcico na qualidade do melão Cantaloupe 'HyMark', minimamente processado e armazenado a $5^{\circ} \mathrm{C}$ por 18 dias.

\section{MATERIAL E MÉTODO}

Foram utilizados melões Cantaloupe 'Hy-Mark' colhidos de plantações comerciais em Mossoró (RN). A colheita foi realizada pela manhã, aos 65 dias após o plantio e as características determinantes para a seleção dos frutos foram camada de abscisão do pedúnculo, apresentando $75 \%$ de desprendimento; coloração verde-escuro da casca; teor de sólidos solúveis igual ou maior que $9^{\circ} 0$ Brix; e uniformidade de tamanho e forma do fruto. Imediatamente após a colheita, os frutos foram transportados, em veículo com ar refrigerado, para o Laboratório de Fisiologia e Tecnologia Pós-colheita da Embrapa Agroindústria Tropical em Fortaleza, onde foram selecionados, sanitizados e submetidos aos tratamentos, em ambiente com um rígido monitoramento de temperatura, mantida em $10 \pm 1^{\circ} \mathrm{C}$ para seleção, sanitização e tratamento dos frutos e $5 \pm 1 \mathrm{C}$ para armazenamento das amostras. Os frutos foram inicialmente lavados com detergente neutro, enxaguados em água corrente, sanitizados em água contendo 200 ppm de hipoclorito de sódio (pH@ 7) e drenados em superfície previamente higienizada, coberta com papel esterilizado.

As instalações utilizadas no processamento, incluindo paredes, pisos, tetos, tanques e mesas, bem como utensílios de corte, foram previamente lavados e enxaguados com água contendo 200 ìg g $^{-1}$ de cloro ativo. Após higienização, a instalação foi mantida fechada e refrigerada a $10^{\circ} \mathrm{C}$ e $90 \pm 5 \%$ UR, dando início à cadeia de frio.

O processamento mínimo foi realizado por operadores adequadamente vestidos e treinados obedecendo às etapas: corte das extremidades; corte transversal dividindo o fruto em metades equivalentes; retirada das sementes e descasque; obtenção de cubos uniformes de 2 a $3 \mathrm{~cm}$ através de cortes transversais seguido de um ou dois cortes longitudinais, de acordo com o tamanho do fruto; imersão por três minutos em 0,5\% ou $1 \%$ de cálcio na forma de cloreto de cálcio $\left(0,18 \mathrm{~g} \mathrm{CaCl} 2.2 \mathrm{H}_{2} \mathrm{O} .100 \mathrm{ml}^{-1} \mathrm{ou}\right.$ $0,36 \mathrm{~g} \mathrm{CaCl}_{2} \cdot 2 \mathrm{H}_{2} \mathrm{O} \cdot 100 \mathrm{ml}^{-1}$, respectivamente) ou imersão em $0,5 \%$ ou $1 \%$ de cálcio na forma de quelato aminocálcico (0,27 g de quelato aminocálcico.100 $\mathrm{mL}^{-1}$ ou 0,55 g de quelato aminocálcico.100 $\mathrm{mL}^{-1}$, respectivamente); acondicionamento das amostras em embalagens de polietileno tereftalato (PET) e armazenamento refrigerado $\left(5 \pm 1^{\circ} \mathrm{C}\right.$ e $90 \pm 5 \%$ UR). As soluções foram preparadas, e o $\mathrm{pH}$ ajustado para 6.0 pela adição de uma pequeníssima quantidade de $\mathrm{HCl}$, imediatamente antes da aplicação dos tratamentos.

As avaliações ocorreram logo após o processamento e em intervalos de 3 dias até o $18^{\circ}$ dia de armazenamento. As medições foram tomadas em cada cubo num total de 10 cubos por repetição. Avaliou-se: a aparência, coloração e firmeza da polpa, teor de cálcio total e solúvel, sólidos solúveis (SS), acidez total titulável (ATT) e potencial hidrogeniônico (pH). Aparência: determinada através de escala hedônica com valores variando de 5 a 1 ( $5=$ aspecto de fruto fresco e ausência de translucência; $4=$ aspecto de fruto fresco mas com possível indicação de translucência; $3=$ surgimento de translucência; 2= levemente deteriorado com sinais visíveis de translucência e polpa levemente descolorada; $1=$ translucência acentuada e/ou sinais de ataque microbiológico). As amostras que obtiveram notas iguais ou inferiores a 3 foram consideradas impróprias para a comercialização. Coloração da polpa: determinada por reflectometria, com um calorímetro Minolta (Croma Meter CR-200b), com valores expressos no módulo L**(luminosidade), a** e b** para posterior cálculo de croma e ânglo hue. Firmeza da polpa: avaliada usando-se texturômetro digital (Stable Micro Systems, modelo TA.XT2) com ponteira cilíndrica de $6 \mathrm{~mm}$ de diâmetro, programada para penetrar aproximadamente $30 \%$ da altura do cubo. As medições foram tomadas quando a temperatura interna das amostras atingiu $21^{\circ \circ} \mathrm{C}$, no centro de um dos lados do cubo, evitando-se a região placentária ou próxima da casca. Os resultados foram expressos em Newton (N). SS: determinado com refratômetro digital (PR-100, Palette, Atago), com compensação automática de temperatura e os resultados expressos em ${ }^{\circ} \mathrm{Brix}$. AT: determinada através de titulação com $\mathrm{NaOH} 0,1 \mathrm{~N}$, com pH até 8,1 em um titulador potenciométrico automático (Mettler DL12) e os resultados expressos em percentagem de ácido cítrico. $\mathrm{pH}$ : determinado no suco, utilizando-se um potenciômetro digital (HI 9321, Hanna instruments). Teores de cálcio total e solúvel: determinados por espectrofotometria de absorção atômica (Alnalyst 300, Perkin Elmer) após digestão nitroperclórica, sendo que as análises de cálcio total seguiram metodologia descrita por Sarruge \& Haag (1974), e as de cálcio solúvel seguiram recomendação de Siddiqui \& Bangerth (1995). O teor de cálcio insolúvel foi obtido através da diferença entre os teores de cálcio total e solúvel. Os resultados foram expressos em mg $\mathrm{g}^{-1}$ de matéria seca.

Utilizou-se o delineamento experimental inteiramente casualisado, em esquema fatorial $5 \times 7$, com três repetições, sendo cada repetição constituída de dez amostras. Os fatores estudados foram doses de cálcio $(0,0,5$ e $1 \%$ de cloreto de cálcio ou quelato aminocálcico) e 7 tempos de 


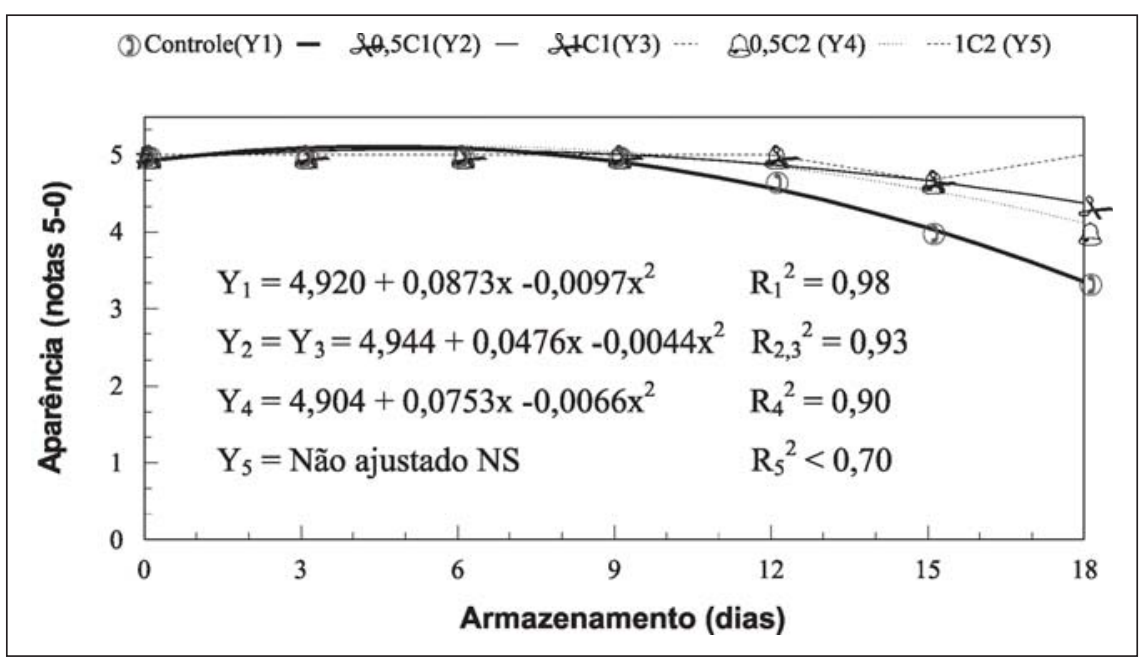

Figura 1. Aparência (escala de notas de 5 a 0) do melão Cantaloupe 'Hy-Mark' minimamente processado, tratado com 0,5 ou $1 \%$ de cálcio na forma de cloreto de cálcio (C1) ou quelato aminocálcico (C2) e armazenado por 18 dias sob refrigeração $\left(5 \pm 1^{\circ} \mathrm{C}\right.$ e $90 \pm 5 \%$ UR). Mossoró, UFERSA, 2005.

armazenamento $(0 ; 3 ; 6 ; 9 ; 12 ; 15$ e 18 dias). As análises estatísticas foram realizadas com o programa computacional SISVAR. Os resultados foram submetidos à regressão polinomial quando pela análise de variância foi constatada a significância, através do teste F, para a interação entre os fatores. Quando a interação não foi significativa, os tratamentos foram comparados através do teste Tukey ao nível de 5\% de probabilidade e o tempo de armazenamento submetido à regressão polinomial. Nos dois casos foram usadas equações de até $3^{\circ}$ grau, com um coeficiente de determinação mínimo de 0,70.

\section{RESULTADOS E DISCUSSÃO}

A aplicação de cálcio na forma de cloreto de cálcio e quelato aminocálcio manteve a aparência das amostras ao longo do período de armazenamento. Enquanto os cubos não tratados preservaram a aparência inicial somente até o sexto dia de armazenamento, os cubos tratados com cálcio mantiveram a aparência inicial até o nono dia (Figura 1). Início de translucência foi observado somente após o décimo segundo dia de armazenamento, quando alguns cubos apresentaram sinais de translucência, independentemente da dose de cálcio aplicada. Ao final do experimento, os cubos tratados com cálcio, com destaque para a aplicação de cálcio na forma de cloreto de cálcio, apresentaram indicação de transluscência, mas preservaram o aspecto de fruto fresco, enquanto nos cubos não tratados verificou-se 0 surgimento de translucência. Estes resultados corroboram com os reportados por Luna-Guzmán et al. (1999) que concluíram que a aplicação de cálcio em melão Cantaloupe minimamente processado favoreceu a aparência dos cubos.

A luminosidade permaneceu estável por todo o período experimental, apresentando valor médio de 65 (dados não apresentados). A estabilidade da luminosidade das amostras pode estar associada ao poder de corte da lâmina utilizada no processamento associado ao monitoramento da baixa temperatura de armazenamento que contribuíram para a redução da atividade das enzimas reponsáveis pelo escurecimento enzimático e retardaram a senescência do tecido. Da mesma forma, Portela \& Cantwell (2001), observaram que amostras de melão Cantaloupe obtidas com lâmina afiada e mantidas sob refrigeração apresentaram menor senescência acompanhada de maior retenção de firmeza, menor ocorrência de translucência e estabilidade da luminosidade.

A intensidade da coloração das amostras, medida pelo ângulo hue e pelo croma, apresentou valores médios de $68,2^{\circ}$ e 34,35 , respectivamente, e manteve-se estável por todo o período ex- perimental (dados não apresentados). Estes resultados são concordantes com os reportados por Arruda at al. (2003), que observaram estabilidade nas características brilho e intensidade de coloração em melão Cantaloupe, cv. " Bônus II”, minimamente processado em cubos e armazenado a $3^{\circ} \mathrm{C}$.

A aplicação de ambas as fontes de cálcio proporcionou maior retenção da firmeza das amostras por todo o período experimental. As amostras tratadas com 0,5 ou $1 \%$ de cálcio na forma de cloreto de cálcio apresentaram 74 e 83\% da firmeza inicial, respectivamente, ao final de dezoito dias, enquanto as amostras tratadas com 0,5 ou $1 \%$ de cálcio na forma de quelato aminocálcico mantiveram 67 e $68 \%$ da firmeza inicial, respectivamente. Neste mesmo período, as amostras do controle apresentaram apenas $57 \%$ da firmeza inicial (Figura 2). Desta forma, ambas as doses e sais de cálcio reduziram o amaciamento das amostras, sendo a aplicação de quelato aminocálcico uma promissora alternativa para a manutenção da firmeza em melão Cantaloupe minimamente processado e armazenado a $5^{\circ} \mathrm{C}$.

Luna-Guzmán et al. (1999), estudando o efeito de diferentes doses de cloreto de cálcio (1-5\%) na firmeza do melão Cantaloupe minimamente processado, observaram que a adição de cálcio reduziu o amaciamento das amostras. No entanto, concentrações iguais ou maiores a $2,5 \%$ conferiram sabores descritos pelos autores como "estranhos".

As concentrações de cálcio total determinadas nas amostras tratadas com cálcio foram duas vezes maiores que as encontradas nas amostras do controle (0,77 $\mathrm{mg} \mathrm{g}^{-1}$ de matéria seca) (Tabela 1$)$. A aplicação de $1 \%$ de cálcio na forma de cloreto de cálcio foi o tratamento que apresentou os maiores teores de cálcio total, seguido da aplicação de $0,5 \%$ deste mesmo sal e 0,5 e $1 \%$ de cálcio na forma de quelato aminocálcio. Estes resultados corroboram com estudos recentes em que a adição de cálcio proporcionou o aumento do teor de cálcio e manteve a firmeza das amostras de melão "honeydew" minimamente processado e tratado com cloreto de cálcio ou quelato aminocálcico (Saftener et al., 2003) e melão “Amarillo” minimamente 
Tabela 1. Valores médios dos teores de cálcio total (CT), cálcio solúvel (CS) e cálcio insolúvel (CI), sólidos solúveis (SS), acidez titulável (AT) e pH do melão Cantaloupe 'Hy-Mark’ minimamente processado, tratado com 0,5 ou 1\% de cálcio (Ca) na forma de cloreto de cálcio

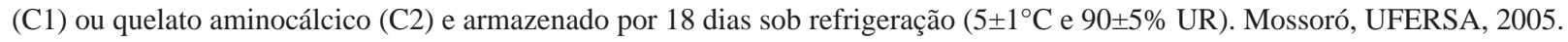

\begin{tabular}{|c|c|c|c|c|c|c|}
\hline & $\begin{array}{l}\mathrm{CT}\left(\mathrm{mg} \mathrm{g^{-1 }} \mathrm{de}\right. \\
\text { matéria seca) }\end{array}$ & $\begin{array}{l}\mathrm{CS}\left(\mathrm{mg} \mathrm{g^{-1 }} \mathrm{de}\right. \\
\text { matéria seca) }\end{array}$ & $\begin{array}{l}\mathrm{Cl}\left(\mathrm{mg} \mathrm{g}^{-1} \mathrm{de}\right. \\
\text { matéria seca) }\end{array}$ & SST ( ${ }^{\circ}$ Brix) & $\begin{array}{c}\text { ATT } \\
\text { (\% ácido cítrico) }\end{array}$ & $\mathrm{pH}$ \\
\hline Controle & $0,77 a^{*}$ & $0,30 a$ & $0,47 a$ & $9,6 b$ & $0,087 a$ & $6,30 \mathrm{c}$ \\
\hline $0,5 \%$ de Ca na forma de $\mathrm{C}^{1}$ & $1,52 b c$ & $0,66 \mathrm{~cd}$ & $0,85 \mathrm{~cd}$ & $9,3 a$ & $0,097 b$ & $6,14 a$ \\
\hline $1 \%$ de Ca na forma de $C^{1}$ & $1,72 \mathrm{c}$ & $0,75 d$ & $0,97 d$ & $10 c$ & $0,091 \mathrm{ab}$ & $6,21 a b$ \\
\hline $0,5 \%$ de Ca na forma de $C^{2}$ & $1,32 b$ & $0,54 b$ & $0,77 b$ & $9,7 \mathrm{bc}$ & $0,097 b$ & $6,20 \mathrm{ab}$ \\
\hline $1 \%$ de Ca na forma de $C^{2}$ & $1,35 c$ & $0,62 b c$ & $0,73 \mathrm{bc}$ & $9,95 c$ & $0,097 b$ & $6,26 \mathrm{bc}$ \\
\hline
\end{tabular}

*Médias seguidas por letras distintas diferem entre si, ao nível de 5\% de probabilidade, pelo teste de Tukey (means followed by the same letter did not differ from each other, Tukey, 5\%).

processado e tratado com cloreto de cálcio ou lactato de cálcio (Aguayo et al., 2008), sugerindo que o aumento da concentração de cálcio no tecido contribuiu para a manutenção da firmeza.

O teor de cálcio solúvel encontrado nas amostras tratadas com $1 \%$ de ambas as fontes de cálcio superou aquele encontrado nas amostras do controle em aproximadamente $100 \%$ (Tabela 1). Estes resultados corroboram com os reportados por Luna-Guzmán et al. (1999) que observaram que a aplicação de cloreto de cálcio em cilindros de melão Cantaloupe resultou em maior teor de cálcio solúvel nas amostras tratadas.

Os teores de cálcio insolúvel encontrados foram maiores nas amostras tratadas do que nas amostras do controle. Os teores de cálcio insolúvel encontrados nas amostras tratadas com cloreto de cálcio foram maiores que os das amostras tratadas com quelato aminocálcico. No entanto, ambos os tratamentos continham a mesma concentração de cálcio para cada dose testada. Da mesma forma, Aguayo et al. (2008) estudando o efeito da aplicação de $0,5 \%$ de cálcio nas formas de cloreto, carbonato e lactato de cálcio, na qualidade do melão “Amarillo” minimamente processado observaram que a aplicação da mesma quantidade de cálcio proveniente de diferentes fontes resultou em diferentes concentrações de cálcio insolúvel no tecido, com a aplicação de 0,5\% de cálcio na forma de cloreto de cálcio apresentando maior concentração de cálcio ligado e maior retenção da firmeza. Desta forma, outros fatores, tais como solubilidade do sal e capacidade de difusão deste dentro do tecido devem ser considerados no estudo da extensão

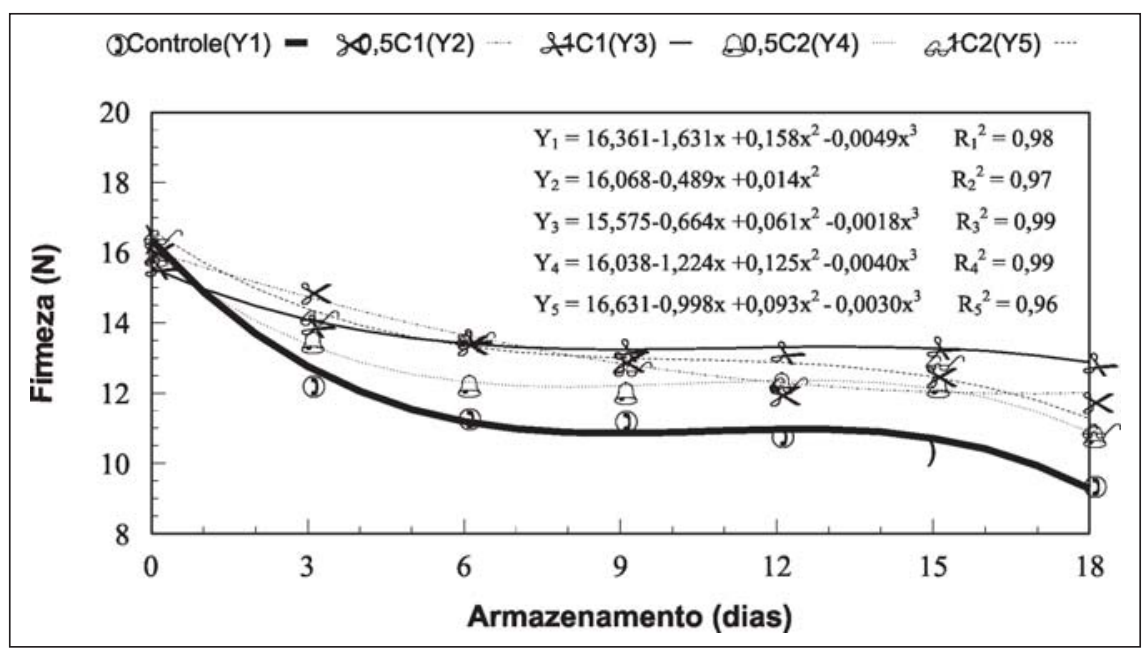

Figura 2. Firmeza (N) da polpa do melão Cantaloupe ‘Hy-Mark’ minimamente processado, tratado com 0,5 ou $1 \%$ de cálcio na forma de cloreto de cálcio (C1) ou quelato aminocálcico (C2)

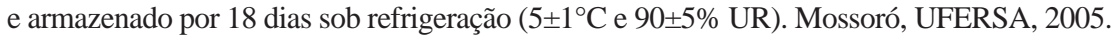

da qualidade do melão Cantaloupe minimamente processado. A redução no amaciamento do tecido, proporcionada pela adição de cálcio, pode ser atribuída à preservação da estabilização da membrana pela interação dos íons de cálcio com os compostos pécticos da lamela média e da parede celular formando um complexo cálcio-pectina que proporciona o aumento na rigidez das mesmas (Poovaiah, 1986), tornando-as mais resistentes ao ataque da poligalacturonase (Buescher \& Hobson, 1982) e mantendo a pressão de turgor da célula (Mignani et al., 1995).

O teor de SS manteve-se estável por todo o período experimental (Tabela 1). Os tratamentos $1 \%$ de cálcio na forma de cloreto de cálcio e quelato aminocálcico apresentaram os teores de SS mais elevados (Tabela 1).

AATT apresentou um ligeiro aumento com o decorrer do tempo de armazenamento, com valores inicial e final de 0,085 e 0,105\% de ácido cítrico, respectivamente (Tabela 1). Os tratamentos controle e $1 \%$ de cálcio na forma de cloreto de cálcio apresentaram os menores valores com 0,087 e $0,091 \%$ de ácido cítrico, respectivamente. Os demais tratamentos apresentaram valor médio de 0,097\% de ácido cítrico. O leve aumento observado na ATT do melão Cantaloupe 'Hy-Mark' verificado neste experimento foi também reportado por Machado et al. (2004) em melão Cantaloupe minimamente processado e armazenado a $5^{\circ} \mathrm{C}$ por 21 dias.

$\mathrm{O} \mathrm{pH}$ não apresentou diferenças significativas $(p £ 0,05)$ durante o período experimental e apresentou valores mínimos de 6,10 e máximo de 6,29. A estabilidade do $\mathrm{pH}$ está provavelmente associada às baixas temperaturas. Lamikanra et al. (2000) também não observaram mudanças significativas nos teores de pH de melão Cantaloupe mi- 
nimamente processado e armazenado a $4^{\circ} \mathrm{C}$ por 14 dias.

A aplicação de 0,5 ou 1,0\% de cálcio na forma de cloreto de cálcio ou quelato aminocálcico manteve a qualidade do melão Cantaloupe "Hy-Mark", sob as condições estudadas, através da manutenção da firmeza e da aparência das amostras. O uso do quelato aminocálcico mostrou ser uma alternativa adequada para a extensão da vida útil do melão Cantaloupe sob as condições citadas neste trabalho. O uso do cloreto de cálcio a 1\% manteve a firmeza inicial das amostras até o final do período de armazenamento e proporcionou os maiores teores de cálcio insolúvel, consequência da maior solubilidade e facilidade de difusão no tecido. A qualidade inicial dos frutos, o préresfriamento, o poder de corte da lâmina utilizada no processamento, aliados a um rígido controle de temperatura, contribuíram para a estabilidade da luminosidade e intensidade da coloração da polpa do fruto cortado.

\section{REFERÊNCIAS}

ALBION LABORATORIES. 1998. What's new with Albion. Albion Research Notes v.7, n.1.

AGUAYO E; VÍCTOR H; ARTÉS. EF. 2008. Effect of hot water treatment and various calcium salts on quality of fresh-cut 'Amarillo' melon, Postharvest Biology and Technolology 47: $397-406$.
ARRUDA MC; JACOMINO AP; SARANTÓPOULOS CIGL; MORETTI CL. 2003. Qualidade de melão minimamente processado armazenado em atmosfera modificada passiva. Horticultura Brasileira 21 655-659.

BUESCHER RW; HOBSON GE. 1982. Role of calcium and chelating agents on regulating the degradation of tomato fruit tissue by polygalacturonase. Journal of Food Biochemistry 6: 147-160.

CONWAY WS. 1989. Altering nutritional factors after harvest to enhance resistance to postharvest disease. Phytopathology 79: 13841387.

LESTER EG; GRUSAK MA. 1999. Postharvest Application of Calcium and Magnesium to Honeydew and Netted Muskmelon: Effects on Tissue Ion Concentration, Quality, and Senescence. Journal of American Society for Horticultural Science 124: 545-552.

LAMIKANRA O; CHEN JC; BANKS D; HUNTER PA. 2000. Biochemical and microbiological changes during the storage of minimally processed cantaloupe. Journal of Agriculture and Food Chemistry 48: 59555961.

LUNA-GUZMÁN I; BARRETT DM. 2000. Comparison of calcium chloride and calcium lactate effectiveness in maintaining shelf stability and quality of fresh-cut cantaloupes. Postharvest Biology and Technology 19: 6172.

LUNA-GUZMÁN I; CANTWELL MI; BARRETT DM. 1999. Fresh-cut cantaloupe: effects of $\mathrm{CaCl}_{2}$ dips and heat treatment on firmness and metabolic activity. Postharvest Biology and Technology 17: 201-213.

MACHADO FLC; MAIA GA; FIGUEREDO RW; ALVES RE. 2004. Conservação de melão cantaloupe minimamente processado, após a plicação de 1-MCP. Revista Ciência Agronômica 35: 394-398.
MIGNANI I; GREVE LC; BEN-ARIE R; STOTZ HU; LI C; SHACKEL K; LABAVITCH J. 1995. The effects of $\mathrm{GA}_{3}$ and divalent cations on aspects of pectin metabolism and tissue softening in ripening tomato pericarp. Physiologia Plantarum 93: 108-115.

POOVAIAH BW. 1986. Role of calcium in prolonging storage life of fruits and vegetables. Food Technology 40: 86-89.

PORTELA SI; CANTWELL MI. 2001. Cutting blade sharpness affects appearance and other Quality attributes of fresh-cut cantaloupe melon. JFS: Food Chemistry and Toxicology 66: 1265-1270.

SAFTNER RA; BAI J; ABBOTT JA; LEE YS. 2003. Sanitary dips with calcium propionate, calcium chloride, or a calcium amino acid chelate maintain quality and shelf stability of fresh-cut honeydew chunks. Postharvest Biology and Technology 29: 257-269.

SALTVEIT ME. 2000. Fresh-cut product biology. Fresh-cut products: maintaining quality and safety. 12 a 14 de setembro. University of California: Davis, California.

SARRUGE JR; HAAG HP. 1974. Análises químicas em plantas. Piracicaba: ESALQUSP, 56p.

SIDDIQUI S; BANGERTH F. 1995. Differential effect of calcium and strontium on flesh firmness and properties of cell wall in apples. Journal of Horticultural Science 70: 949-953.

SZCZESNIAK AS. 2002. Texture is a sensory property. Food Quality and Preference 13: 215-225. 